\title{
Hybrid Vibration Control under Broadband Excitation and Variable Temperature Using Viscoelastic Neutralizer and Adaptive Feedforward Approach
}

\author{
João C. O. Marra, ${ }^{1}$ Eduardo M. O. Lopes, ${ }^{1}$ \\ José João de Espíndola, ${ }^{2}$ and Walter Antônio Gontijo ${ }^{3}$ \\ ${ }^{1}$ Universidade Federal do Paraná, Departamento de Engenharia Mecanica, Rua Coronel Francisco H. dos Santos, $s / n$, \\ Bloco IV, Centro Politécnico, 81530-900 Curitiba, PR, Brazil \\ ${ }^{2}$ Universidade Federal de Santa Catarina, Rua Voluntario Fernando Caldeira 87, 88085-290 Florianopolis, SC, Brazil \\ ${ }^{3}$ Universidade Federal de Santa Catarina, Departamento de Engenharia Elétrica, LINSE, Caixa Postal 476, \\ 88040-900 Florianópolis, SC, Brazil
}

Correspondence should be addressed to João C. O. Marra; joaocmarra@yahoo.com.br

Received 2 January 2016; Revised 11 April 2016; Accepted 1 June 2016

Academic Editor: Londono Monsalve

Copyright (C) 2016 João C. O. Marra et al. This is an open access article distributed under the Creative Commons Attribution License, which permits unrestricted use, distribution, and reproduction in any medium, provided the original work is properly cited.

\begin{abstract}
Vibratory phenomena have always surrounded human life. The need for more knowledge and domain of such phenomena increases more and more, especially in the modern society where the human-machine integration becomes closer day after day. In that context, this work deals with the development and practical implementation of a hybrid (passive-active/adaptive) vibration control system over a metallic beam excited by a broadband signal and under variable temperature, between 5 and $35^{\circ} \mathrm{C}$. Since temperature variations affect directly and considerably the performance of the passive control system, composed of a viscoelastic dynamic vibration neutralizer (also called a viscoelastic dynamic vibration absorber), the associative strategy of using an active-adaptive vibration control system (based on a feedforward approach with the use of the FXLMS algorithm) working together with the passive one has shown to be a good option to compensate the neutralizer loss of performance and generally maintain the extended overall level of vibration control. As an additional gain, the association of both vibration control systems (passive and active-adaptive) has improved the attenuation of vibration levels. Some key steps matured over years of research on this experimental setup are presented in this paper.
\end{abstract}

\section{Introduction}

In passive vibration control, the successful use of dynamic vibration neutralizers (also called dynamic vibration absorbers) is long recognized [1-4]. Particularly, it has already been shown that dynamic vibration neutralizers (DVN) of viscoelastic nature can be efficaciously designed to optimally promote vibration control over an extended frequency range and at a given temperature $[5,6]$. However, as viscoelastic materials are not only frequency but also temperature dependent [2], detuning (operation away from optimal conditions) can occur, reducing the performance of the neutralizers. A feasible alternative would then be the use of a hybrid (passive + active) vibration control scheme.

The interest in hybrid (passive + active/semiactive) vibration control systems has increased fast in the last decades [7-13], especially because it has been observed that passive and active control systems are well complementary [14, 15]. Additionally, the evolution of materials, sensors, actuators, DSP's, and signal transmission techniques has simplified implementation and increased feasibility of application in many areas of interest in vibration control.

A passive vibration control system (PVCS) usually contributes robustness, while an active vibration control system 


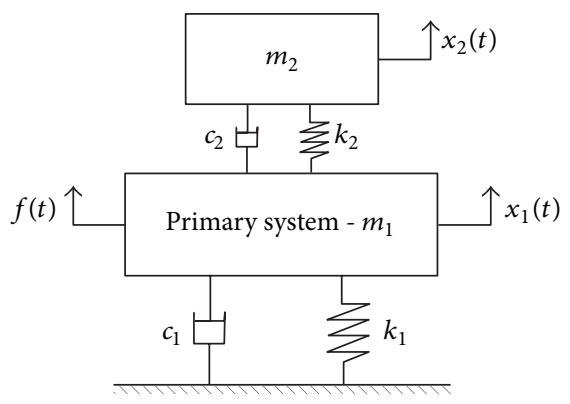

(a)

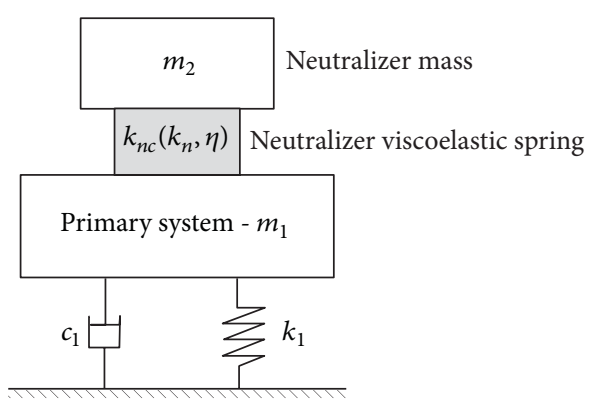

(b)

FIGURE 1: Schema of a (a) conventional (b) viscoelastic dynamic vibration neutralizer applied to a primary system.

(AVCS) contributes flexibility. Thus, the association in parallel (i.e., in the same frequency range) of these two systems permits the design of a very high performance hybrid vibration control system (HVCS), with robustness, flexibility, and reliability.

In general, passive vibration control techniques are based on fixed modifications of stiffness, mass, and/or damping characteristics of the mechanical system of concern $[4,16]$. These techniques, of relatively low cost, can provide great results when working in stable environments. Their disadvantage is, exactly, the reduced flexibility when any modifications or adjustments are needed.

On the other hand, fully active vibration control techniques are based on strategies of destructive interference [17]. They are commonly implemented through sensors, actuators, and, particularly, a DSP (digital signal processor), which is able to process some input information of concern and generate the control action (based on the implemented algorithm) to be applied to the mechanical system, in order to reduce its original vibration.

In a feedback control approach, the controller works with information on the vibration of the mechanical system whereas, in feedforward control strategies, information on the disturbance is of primary interest. In the latter, the capability of adapting the controller transfer functions, according to some predefined criteria, is usually present, allowing any modifications on the excitation and/or in the mechanical system to be accounted for [18]. So, the key advantages of active vibration control techniques are flexibility and, in some cases, adaptability, at the expense of demand of external power.

In this work, a hybrid vibration control system (HVCS) is introduced and discussed, designed to attenuate vibrations in a metallic beam under broadband excitation and variable temperature. It combines a viscoelastic dynamic vibration neutralizer (VDVN), of passive nature, with components of fully active vibration control in an adaptive feedforward control approach (presented in [19]). Fundamental concepts on those elements are given below, followed by the explanation of the adopted methodology and the presentation of the results concerning the effectiveness and adaptability of the hybrid vibration control system.

It is shown that this association in parallel of a passive vibration control system (PVCS) with an active vibration control system (AVCS) handles successfully the matter of detuning, given the adaptive nature of the AVCS. Besides, it also extends and maintains, in most cases, the overall level of vibration attenuation, over a broad frequency range. To the authors' knowledge, no such system has ever been clearly presented as done herein.

\section{Fundamental Concepts}

2.1. Passive Vibration Control System (PVCS). In the current application, the passive vibration control system (PVCS) consists of a viscoelastic dynamic vibration neutralizer (VDVN). As seen in Figure 1(a), in a simplified and usual form, a dynamic vibration is a secondary system (in this case, with mass $m_{2}$, stiffness constant $k_{2}$, and damping coefficient $c_{2}$ ), added to a primary mechanical system (with mass $m_{1}$, stiffness constant $k_{1}$, and damping coefficient $c_{1}$ ), the vibration of which is desired to be controlled. In Figure 1(a), $f(t)$ is the excitation on the primary system, $x_{1}(t)$ the corresponding vibration, and $x_{2}(t)$ the secondary system (neutralizer) vibration. A dynamic vibration neutralizer can be designed to work either in a tonal frequency or under broadband excitation.

It should be stressed that the use of the above DVN transforms the primary mechanical system (plant) into a twodegree-of-freedom system, the natural frequencies of which are different from those of the primary and the secondary systems alone, according to designer's interests. The damping of the DVN is related to its frequency band of action. The design parameters must be well chosen in order to attain a good control system.

In the case of a viscoelastic neutralizer (VDVN), its characteristics of stiffness and damping are determined by the viscoelastic material employed in the device $[5,6,20]$. For a single degree-of-freedom VDVN, represented in Figure 1(b) by a lump of mass $m_{2}$ and a viscoelastic spring, these characteristics can be described by the complex stiffness $k_{n c}$ of the viscoelastic spring, which is a function of frequency and temperature and given by

$$
k_{n c}(\omega, T)=k_{n}(\omega, T)[1+j \eta(\omega, T)],
$$

where $k_{n}(\omega, T)$ is the dynamic stiffness, $\eta(\omega, T)$ the corresponding loss factor, $T$ the temperature, and $\omega$ the frequency. 


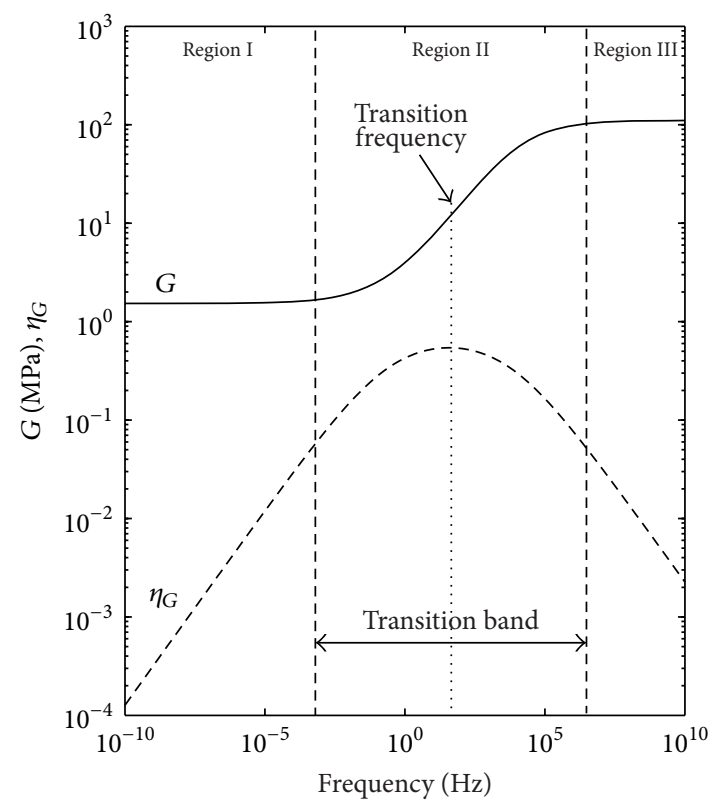

(a)

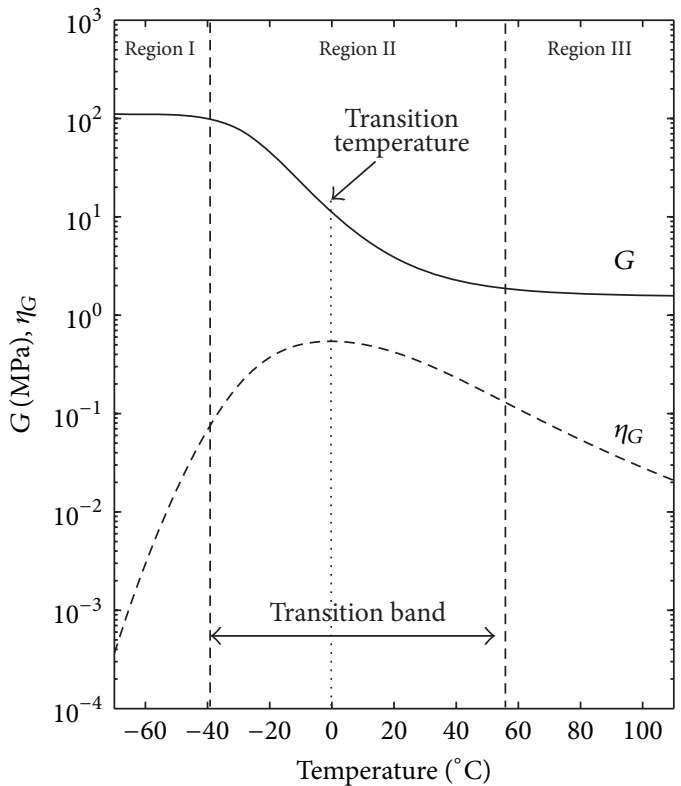

(b)

FIGURE 2: Dynamic shear modulus and loss factor as functions of (a) frequency and (b) temperature.

The stiffness $k_{n c}$ is complex and frequency and temperature dependent because it is related to the modulus of elasticity of the viscoelastic material, which is also complex and frequency and temperature dependent. Each modulus of elasticity can be written in terms of a dynamic modulus and the corresponding loss factor, in the same way as the complex stiffness. Figure 2 shows the typical behavior of the dynamic shear modulus and the corresponding loss factor of a viscoelastic material as functions of frequency and temperature. The way the complex moduli of viscoelastic materials can be modeled by fractional derivatives and then experimentally determined can be found in $[2,21]$.

The single degree-of-freedom VDVN is characterized by its antiresonant frequency, $\Omega_{n}$, which is such that

$$
\Omega_{n}^{2}=\frac{k_{n}\left(\omega_{n}\right)}{m_{n}},
$$

where $k_{n}\left(\omega_{n}\right)$ is the dynamic stiffness of the viscoelastic spring at the antiresonant frequency $\Omega_{n}$ and at a given constant temperature.

The VDVN can be designed to work, in an optimal way, in the so-called "transition band," where the material loss factor is maximum (see Figure 2). That implies a larger frequency band in the vibration attenuation. The optimization process seeks to determine the optimal antiresonant frequency, $\Omega_{n}$ (which constitutes the design vector), by minimizing the Euclidean norm of the vector composed of the maximal absolute values of the principal coordinates of the primary system, over the frequency range of concern (this Euclidean norm is then the objective function).

The above optimization process, carried out by nonlinear techniques, corresponds to the reduction of the frequency response function amplitudes of the primary system in the chosen range. It is highlighted that the VDVN is modeled in the optimization process by the concept of generalized equivalent parameters. By that concept, the compound system (primary + secondary) is described only in terms of the generalized coordinates of the primary system. The design process is fully described in De Espíndola et al. [5], Espíndola et al. [6], and Doubrawa Filho et al. [22] and is not repeated herein for the sake of conciseness.

The PVCS (VDVN), as part of the HVCS investigated in this work, is illustrated in Figure 3.

2.2. Active Vibration Control System (AVCS). An active vibration control system (AVCS) can be implemented in different ways, regarding the architecture, control algorithm, types of sensors and actuators, available signals, and operational conditions. As previously mentioned, two basic control approaches can be listed: feedback and feedforward [17]. The latter is the one employed in the present work, given that some knowledge on the primary excitation (disturbance) can be acquired.

Generally speaking, the basic components of a feedforward control system are a sensor, which captures the input (reference) signal related to the primary excitation, a controller (or control unit), which processes the input signal according to a given algorithm and generates the output (control) signal, and an actuator, which applies the output signal in the system to be controlled. There should also be a second sensor, which captures the net response (error) signal. In the current case, the controller consists primarily of a digital finite impulse response (FIR) filter of adaptive nature. The feedforward approach usually requires the use of adaptive digital filters in order to track closely what happens to the 


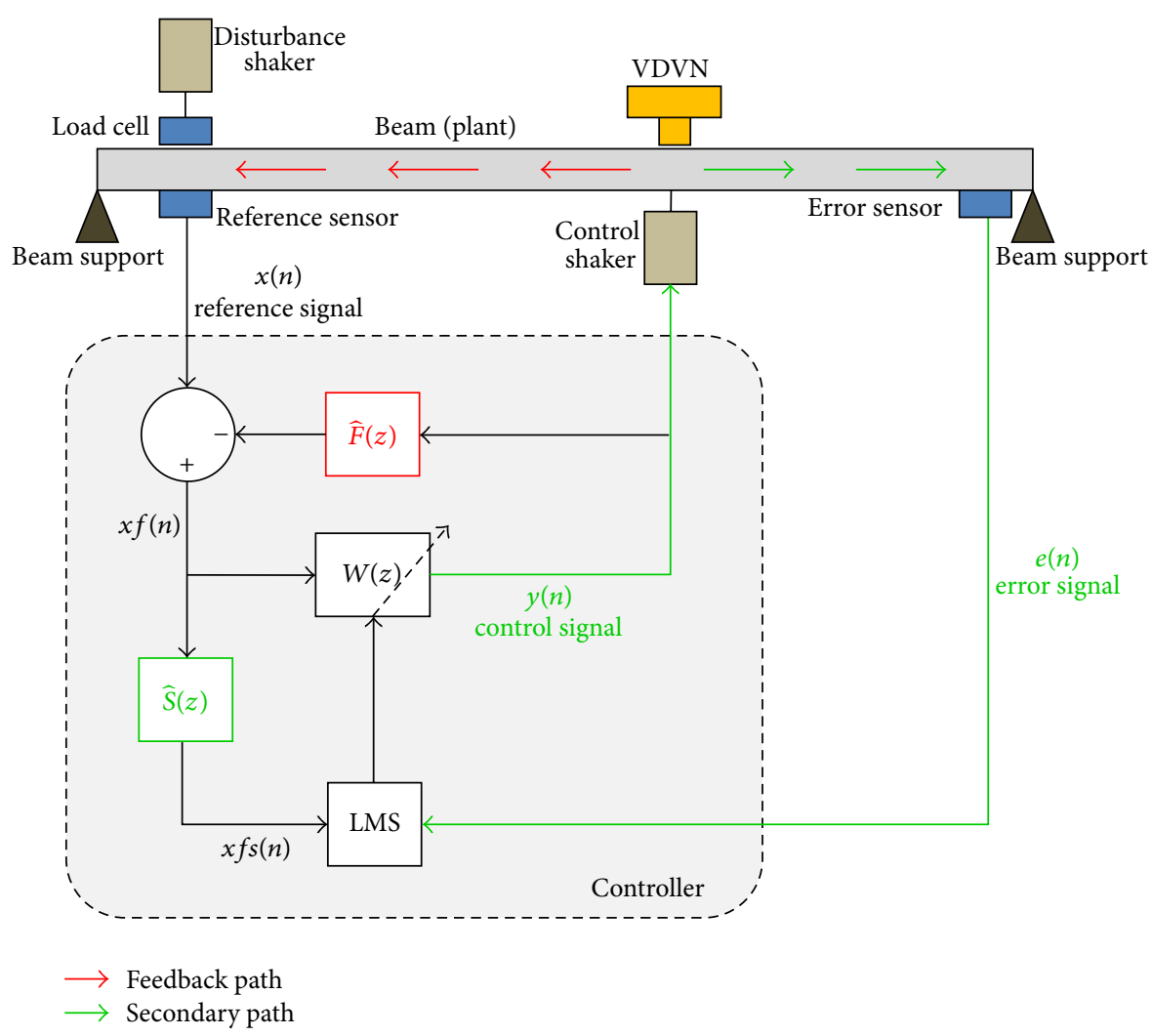

FIgURE 3: Schema of the employed hybrid vibration control system.

system (plant) and generate an efficacious control signal of destructive interference.

Finite impulse response (FIR) filters have, as opposed to infinite impulse response (IIR) filters, the important characteristic of stability; they have no poles in their transfer function. The popularity of FIR filters can also be justified by the fact that the corresponding optimal coefficients can be obtained by an objective function of quadratic nature, with a unique point of minimum. This point can be found in a prompt way through an adaptive algorithm. In the case of IIR filters, the objective function may have several local points of minimum and the algorithm may converge to any of those local points of minimum, instead of the global minimum $[15,23]$. However, as FIR filters are nonrecursive structures, they can demand an excessive number of coefficients to model systems with complex transfer functions, such as vibratory systems with resonances within the frequency band of excitation. It would not be the case of IIR filters, which would require a reduced number of coefficients. [23]

The FIR filter output (control) signal vector $y$ is given by

$$
y(n)=\sum_{i=0}^{N-1} w_{i}(n) x(n-i),
$$

where $n$ is the discrete time, $x$ is the input signal vector, $N$ is the filter size, and $w$ is the filter coefficient vector. In the current work, the coefficients of the adaptive FIR filter (the so-called main filter, which generates the control signal) are obtained by a variant of the well-known LMS algorithm, the FXLMS algorithm. According to this approach, the coefficient vector is updated at each iteration by $[15,23,24]$

$$
w(n+1)=v w(n)+2 \mu e(n) x f_{s}(n)
$$

with $n$ being the discrete time, $w$ the filter coefficient vector, $v$ the so-called leaky factor, $\mu$ the adaptation step size, $e$ the error signal, and $x f s$ the signal vector related to the reference signal (disturbance) properly filtered by feedback and secondary filters. That explains the acronym FXLMS, which stands for filtered- $x$ least mean square.

The AVCS, as part of the investigated HVCS, is displayed in Figure 3. In that figure, the block $W(z)$ represents the main filter, as it is the $z$-transform of $w(n)$, whereas the blocks $\widehat{F}(z)$ and $\widehat{S}(z)$ represent the feedback path and the secondary path estimation filters, respectively. It is observed that the filtered reference signal $x f s(n)$ results from the successive filtering of $x(n)$ by $\widehat{F}(z)$, which gives $x f(n)$, and of $x f(n)$ by $\widehat{S}(z)$.

The concept and the fundamental importance of feedback and secondary paths to the success of a practical implementation of an AVCS must be clear. The feedback path estimation filter $\widehat{F}(z)$ must be inserted in the controller in order to filter the reference (input) signal $x(n)$ (which is captured by the reference sensor) from the physical vibration propagation from the control shaker to the reference sensor, through the metallic beam. Thus, a "clear" reference signal can be delivered to the controller, which is a control law requirement. The secondary path $\widehat{S}(z)$ takes into account 
all the dynamics inherent to the experimental setup, which includes part of the metallic beam, along with the dynamics of transducers, $\mathrm{A} / \mathrm{D}$ and $\mathrm{D} / \mathrm{A}$ converters, amplifiers, and analog filters. These paths are considered in the algorithm through digital FIR filters (nonadaptive), which estimate the real path dynamics (see Figure 3).

According to the design theory of Wiener filters (which are of stochastic origin), the optimal coefficients for FIR filters result from the minimization of the mean square error (MSE), or

$$
\xi=E\left[|e(n)|^{2}\right],
$$

where $e(n)$ is the error signal (see Figure 3) and $E[\cdots]$ the expected value.

In adaptive filtering, as is the current case, the optimal coefficients can be obtained iteratively by LMS (least mean square) algorithms, regarded as practical solutions to Wiener filters [23] where the mean square error (MSE), which is the objective function, is estimated by the instantaneous value of the square of the error signal, in such a way that

$$
\begin{aligned}
\xi & =E\left[|e(n)|^{2}\right] \Longrightarrow \\
\hat{\xi}(n) & =e(n)^{2} .
\end{aligned}
$$

Equation (4) is derived from the equation above and the consideration of the feedback and the secondary paths.

It is observed in Figure 3 that the error signal results, in this case, from the difference between the response to the disturbance shaker and the response to the control shaker (actuator). Both the reference sensor and the error sensor are accelerometers.

The advantages of LMS algorithms are simplicity, reliability, and robustness. On the other hand, a considerable disadvantage is the high dependence of the input signal power spectral density (PSD), so that the more uniform the input signal PSD, the faster the convergence.

A MIMO (multiple input multiple output) application of a very similar AVCS is implemented in an aircraft fuselage section by Marra et al. [25], where the importance of feedback path is reinforced, as well as the efficacious results of the FXLMS algorithm in an adaptive feedforward control strategy.

Another aircraft fuselage section is the plant used by Griffin et al. [26] to demonstrate the feasibility of interior cabin noise reduction via ASAC (active structural acoustic control) and ANC (active noise control) using FXLMS and PCLMS (two variants of LMS algorithm) in an adaptive feedforward approach, where significant noise reduction is obtained.

Zeng et al. [27] present the use of an adaptive feedforward control framework similar to the AVCS employed herein. It is aimed to suppress aircraft structural vibrations induced by gust perturbations, a typical case where the primary system (of aeroelastic nature) has its flexible modes shifted during operation (mass/inertia changes, different atmospheric conditions, etc.), demanding a "smart" algorithm to adapt its control actions to the new system's behavior.

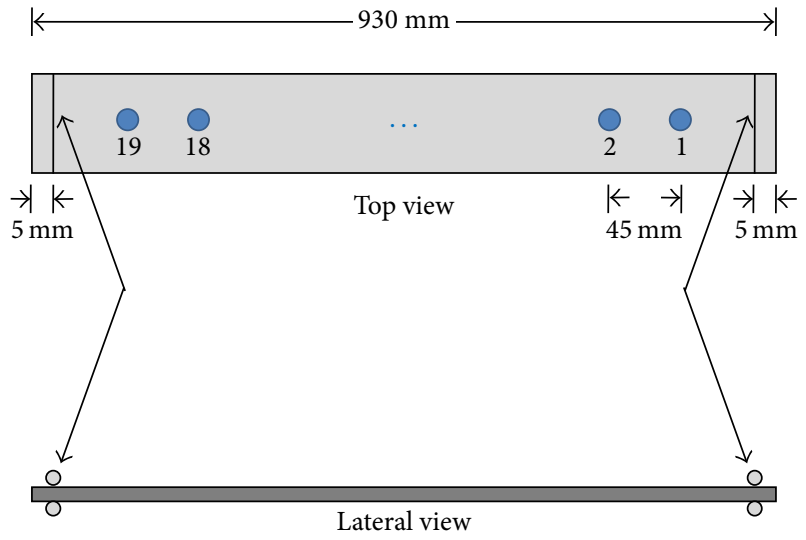

Figure 4: Beam schematic view.

2.3. Hybrid Vibration Control System (HVCS). The above PVCS and AVCS can be combined to form a hybrid vibration control system (HVCS). Apart from dealing with the matter of detuning of a viscoelastic device, an HVCS like this, schematically shown in Figure 3, can offer greater reliability as a global vibration control system, since, in case of failure or loss of performance of any "subsystem," the other one can maintain some overall vibration control level. The methodology employed to implement and evaluate the HVCS is presented in the next section.

\section{Methodology}

The system to be controlled (primary mechanical system, or plant) is a $0.5 \mathrm{~kg}$ simply supported steel beam, the dimensions of which are $930 \times 23 \times 3 \mathrm{~mm}$. A schematic view of the beam is shown in Figure 4.

A previously performed theoretical and experimental modal analysis on the beam provided complete information about the dynamic behavior of the beam at all positions. It led to the selection of the modes and the frequency range of interest and also to the selection of the point in the beam where to locate both the VDVN and the control shaker. The 4 th, 5th, and 6th vibration modes of the beam are chosen because they allow the design of a VDVN with a relatively small amount of mass and compact viscoelastic elements, resulting in a device of reduced size. As shown further (Figure 10), several components of the experimental setup (beam, supports, neutralizer, sensors, actuators, and others) are placed and handled inside a temperature chamber and the use of components of reduced size becomes a requirement. As to the location of the VDVN and the control shaker, point 2 in the above figure is chosen because there are no nodes of the 4th, 5th, and 6th modes at that point, as required, and also by experimental convenience.

The applied excitation signal is a white noise filtered to a band of 200 to $430 \mathrm{~Hz}$. This signal, displayed in the time and frequency domains in Figure 5, only excites the vibration modes of concern of the beam, as shown in the frequency response function (FRF) of Figure 6. In that figure, the response is at point 1 and the excitation at point 19 (see 

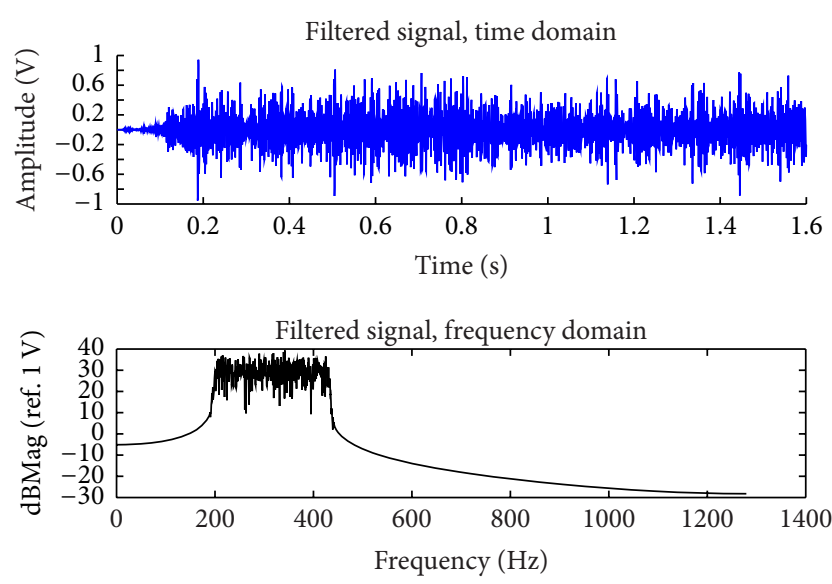

FIGURE 5: Excitation signal (filtered white noise, 200-430 Hz).

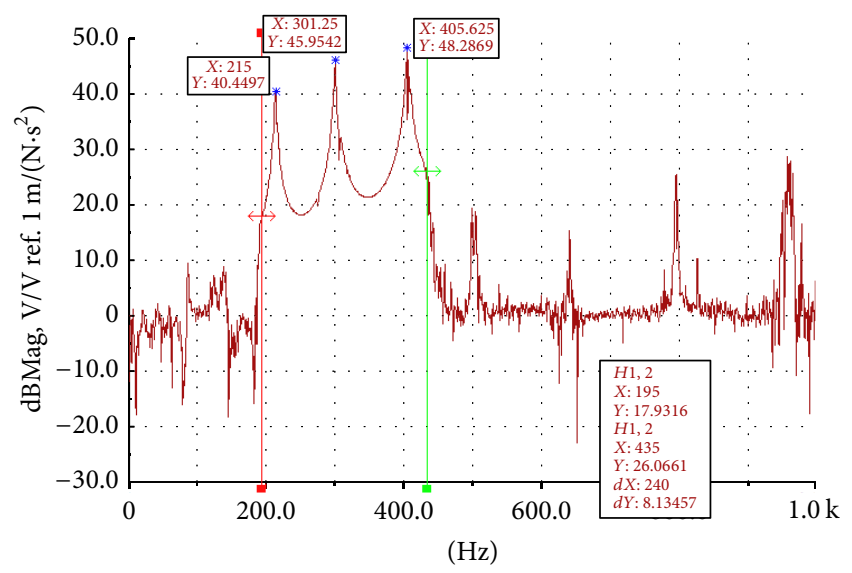

FIGURE 6: FRF (1/19) of the beam without the VDVN and excited in the frequency range of 200 to $430 \mathrm{~Hz}$.

Figure 4), being the corresponding FRF indicated as FRF $(1 / 19)$. This combination of response and excitation points provides clear and expressive results and is selected as the reference in this work.

The PVCS, a viscoelastic DVN with a steel lump of mass of $0.0335 \mathrm{~kg}$ and two elements of butyl rubber 45 Shore $\mathrm{A}$, is optimally designed to act in the frequency band of 190 to $440 \mathrm{~Hz}$ and at the temperature of $25^{\circ} \mathrm{C}$ [28]. The drawings of the VDVN are displayed in Figure 7 whereas the viscoelastic material properties of the employed butyl rubber are shown in the nomogram of Figure 8. This nomogram is the standard plot for displaying dynamic properties of viscoelastic materials [2]. As mentioned earlier, the VDVN is installed at a point where there are no nodes for the vibration modes of interest. The relative positioning of the VDVN and of all the AVCS components (such as sensors and actuators) can be schematically seen in Figure 3.

The controller is based on an Analog Devices board, the EZ-KIT Lite ADSP 21161N, on which the FXLMS algorithm is implemented. Before running the control tests, identification routines for the secondary and feedback paths have to be
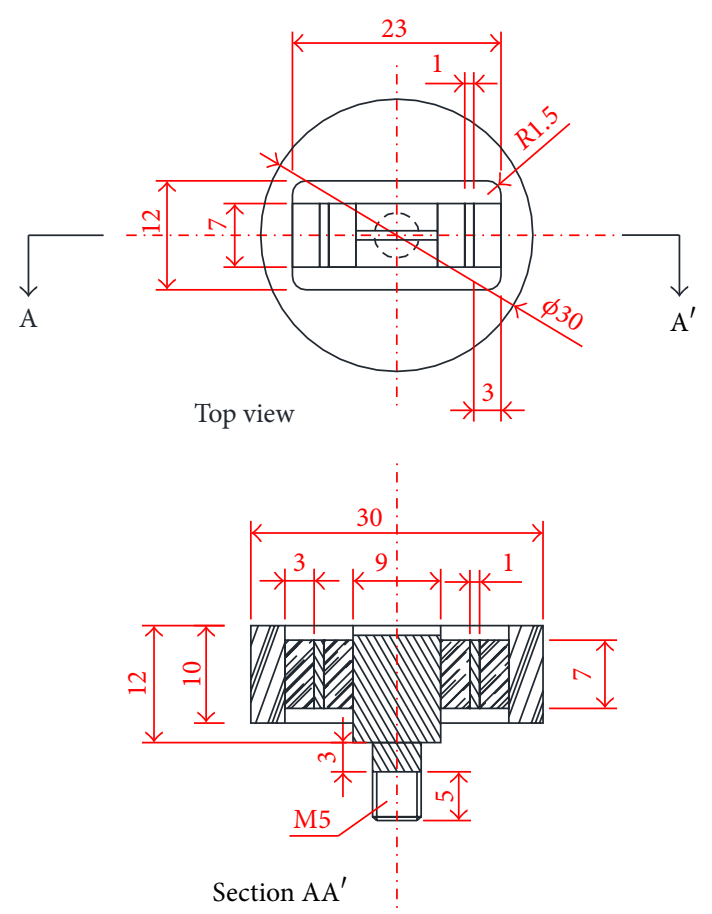

VIII Steel

MU. Aluminium

Bytyl rubber

FIGURE 7: VDVN drawings (all dimensions are in millimeters).

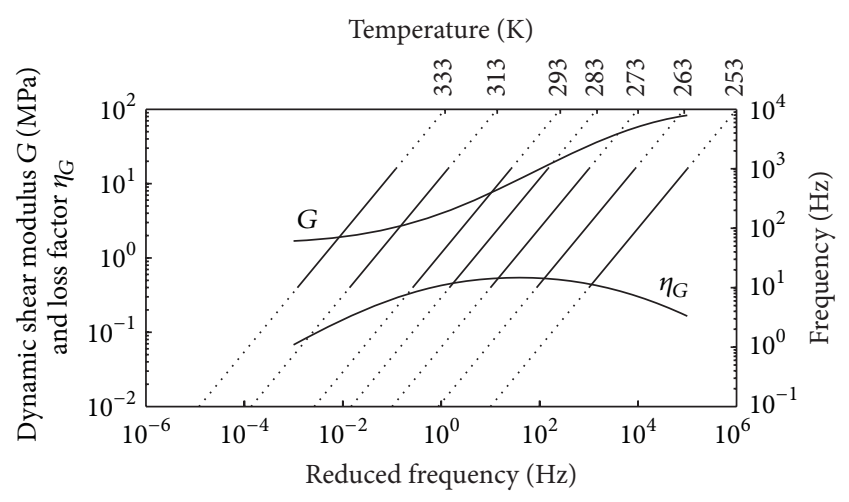

FIgURE 8: Viscoelastic material properties of the butyl rubber.

performed, in order to have the FXLMS algorithm fully implemented, as portrayed in Figure 3. Those paths are identified through offline procedures [29] and the digital filter associated with each path represents the corresponding impulsive response. These filter coefficients are loaded into the algorithm and kept constant, describing thus "static filters" during the control tests.

It should be clear, however, that the main FIR filter, $W(z)$, is not "static" like the secondary and feedback filters, but adaptive, with its coefficients being adjusted at each algorithm iteration according to (4), in an online, real time updating procedure. The use of online identification techniques for the 
TABLE 1: FXLMS optimal parameters for active-adaptive vibration control.

\begin{tabular}{lllcc}
\hline$N$ & $N s$ & $N f$ & $v$ & $\mu$ \\
\hline 300 & 500 & 500 & 0,9999995 & $1,50 E-06$ \\
\hline
\end{tabular}

secondary and feedback paths, although not employed in this investigation, is also possible and has already been reported as advantageous [30].

As observed in Coan Jr. [28], in a previous implementation of an active-adaptive vibration control system, the task of tuning the FXLMS algorithm is very important and deserves special care, because of its high influence on performance. The best tuning parameters found in this work, after experimenting various alternatives, are shown in Table 1 , where $N, N s$, and $N f$ are the number of coefficients of the main filter, $W(z)$; the secondary path filter, $\widehat{S}(z)$; and the feedback path filter, $\widehat{F}(z)$, respectively.

In Table 1, it is observed that the main filter size (300 coefficients) is smaller than those of the secondary and feedback filters (500 coefficients). The main filter is adaptive and its coefficients have to well identify the plant's behavior at only one temperature, which is the current test temperature. That is, the main filter performance is optimized at each temperature. On the other hand, the secondary and feedback filters are not adaptive and, consequently, their performances are not optimized at each test temperature. Thus, the corresponding filter coefficients must describe satisfactorily the plant's behavior at all test temperatures without any change. That suggests that significantly smaller secondary and feedback filters can be attained if they also become adaptive. Smaller filters could improve the algorithm effectiveness as a whole.

As previously mentioned, the digital filters intend to represent the impulsive response of a specific system (for instance, the plant, the secondary path, or the feedback path). So, the more information is acquired by the digital filter about the impulsive response of the system of concern, the higher is the fidelity of such a digital model, that is, the better is the quality of identification.

Figure 9 shows that, for a given filter size, a more damped system is better identified by digital filters than a less damped one. That is due to the amount of "meaningful information" (in terms of impulsive response, $h(t)$ ) acquired by the digital filters regarding the system under identification; that is, it is possible to acquire more impulsive response information from a highly damped system than from a lesser damped system, as seen in Figure 9. Therefore, the main filter can have its task of representing the mechanical system (the metallic beam, in the case) facilitated by the presence of the PVCS, given the damping it introduces in the compound system and the relation between damping and length of impulsive response.

The experimental setup, which allows all the investigations regarding the vibration control systems, is displayed in Figure 10, inside the temperature chamber employed in the measurements.

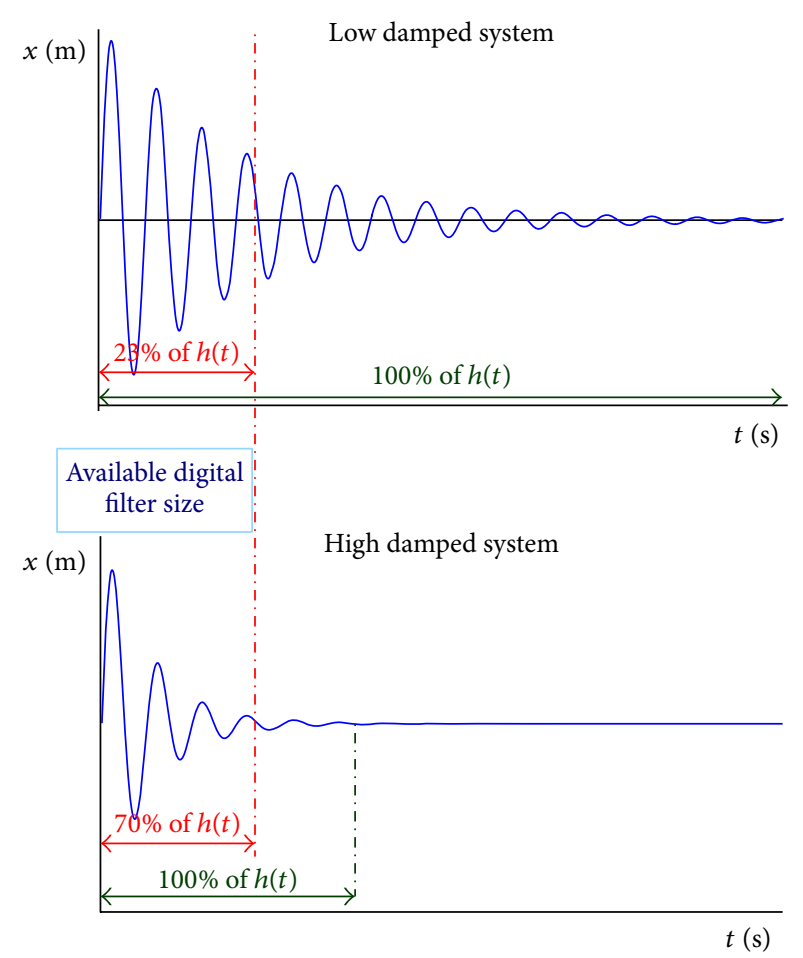

FIGURE 9: Portion of system impulsive response acquired with a given digital filter size.

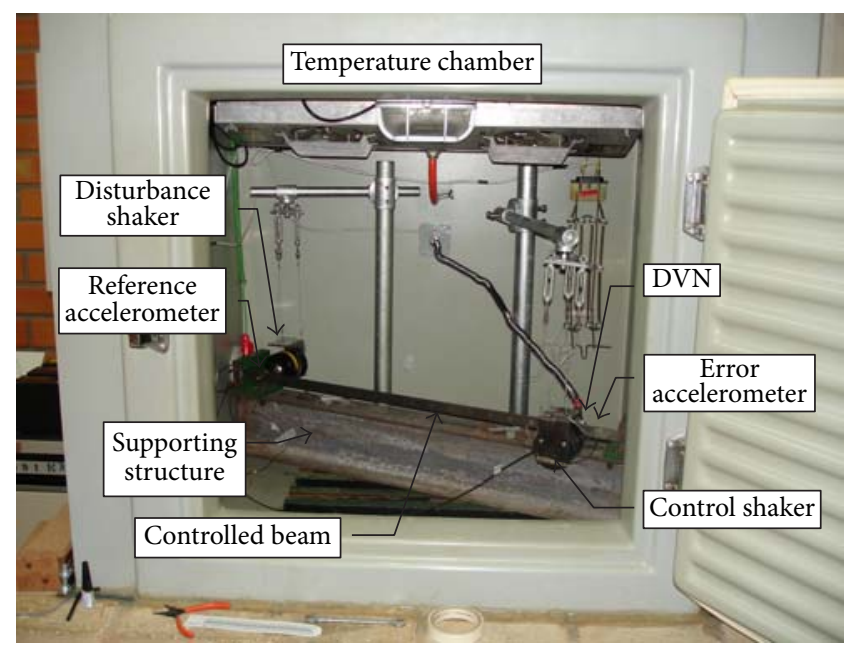

FIGURE 10: Experimental setup inside the temperature chamber.

In a first stage, for the beam alone, the ratio of the acceleration (at a point of the beam) to the disturbing force is computed, in the frequency domain. That ratio is denominated herein a response to force ratio (RFR). After installing the VDVN and maintaining exactly the same primary excitation (disturbance) applied before, it is possible to evaluate the PVCS attenuation performance by computing a response to force ratio (RFR) of the compound system (beam + VDVN). 
An explanation should be given at this point. A response to force ratio (RFR) is a ratio between the response at a point in the system of concern and the disturbing force at the same or at other points, in the frequency domain [15]. This frequency function is introduced to provide a common ground in which all the attenuation performances can be compared. When only the disturbing force acts on the system (beam alone or beam + VDVN), an RFR is a frequency response function (FRF). When the disturbing force acts on the system simultaneously to another external force as, in the current case, the force of destructive interference, an RFR is no longer an FRF. Even though the RFR reveals the changes which take place in the system when the AVCS works on it and allows valid comparisons to be made with other RFRs, exactly the same disturbance force is applied on all the three experimental setups (pure beam, beam + VDVN, and beam + VDVN + AVCS).

After exclusively testing the PVCS, the AVCS is turned on, so to act on the compound system (beam + VDVN), and its additional contribution is evaluated by an RFR of the global system (beam + VDVN + AVCS), still keeping the same disturbance. All those tests are run at room temperature (around $25^{\circ} \mathrm{C}$, the optimal VDVN design temperature).

The next stage is to test the adaptability of the main digital filter of the AVCS, which is carried out by varying the temperature under which the experimental setup is, inside the temperature chamber, as seen in Figure 10. By varying the temperature, it is expected that the VDVN performance deteriorates and the coefficients of the main filter are automatically adjusted in response to that, according to (4), such that the AVCS still maintains a satisfactory vibration level.

Those adaptability tests are performed at the temperatures of $5,15,25$, and $35^{\circ} \mathrm{C}$. At each test temperature, before taking the measurements, a 30-minute interval is considered to allow the temperature of the viscoelastic elements of the VDVN to stabilize. All the RFRs are computed between the error sensor location point (point 1) and the disturbance actuator location point (point 19). Those locations are shown in Figures 4 and 10.

The attenuations obtained in each test condition are calculated according to (7). This equation, introduced in this work, is used to verify the effectiveness of the vibration control systems in their actions over the whole frequency band of interest, in addition to the check in individual frequencies, as usually done:

$$
\operatorname{Att}[\mathrm{dB}]=20 \log _{10}\left\{\frac{\left[\sum_{j} y_{j}^{2}\left(f_{j}\right)\right]^{1 / 2}}{\left[\sum_{j} x_{j}^{2}\left(f_{j}\right)\right]^{1 / 2}}\right\} .
$$

In the above equation, $y_{j}$ represents RFR (response to force ratio) magnitudes along frequencies $f_{j}$, when any control system is $\mathrm{ON}$, that is, plant with any vibration control system. As to $x_{j}$, it represents the corresponding RFR magnitudes when that control system is OFF, that is, plant without that vibration control system. In this context, the term "vibration control system" can be applied either to the PVCS or to the HVCS, bearing in mind the primary

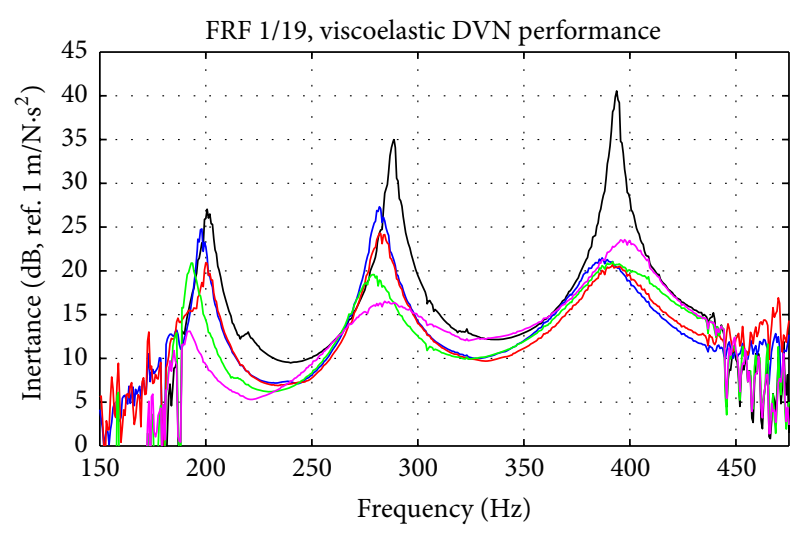

$\begin{array}{ll}\text { - Beam without DVN } & \text { With DVN }, T=25^{\circ} \mathrm{C} \\ \text { - With DVN, } T=5^{\circ} \mathrm{C} & \text { With DVN, } T=35^{\circ} \mathrm{C} \\ \text { - With DVN, } T=15^{\circ} \mathrm{C} & \end{array}$

FIGURE 11: Passive vibration control system (viscoelastic DVN) performance.

TABLE 2: VDVN performance (vibration attenuation), broadband analysis.

\begin{tabular}{lc}
\hline Test temperature $\left[{ }^{\circ} \mathrm{C}\right]$ & RMS broadband attenuation $[\mathrm{dB}]$ \\
\hline 5 & 7,9 \\
15 & 9,1 \\
25 & 9,5 \\
35 & 8,9 \\
\hline
\end{tabular}

goal of dealing with the detuning of the PVCS. Equation (7) represents the root mean square (RMS) value of the vibration attenuation due to each particular vibration control system, in the frequency band of concern.

The corresponding results are presented below.

\section{Results}

The results are as follows.

4.1. Passive Vibration Control System (PVCS). Figure 11 depicts the effectiveness of the VDVN over the frequency band of interest, including the specific and characteristic reductions at the resonance peaks.

It is expected that the VDVN performance varies markedly with the temperature, due to the behavior of the viscoelastic material (see Figures 2 and 8 ) and that is confirmed. In a broadband analysis, which is carried out with the aid of (7), there is loss of performance when the temperature is different from the design value of $25^{\circ} \mathrm{C}$, as observed in Table 2 and in Figure 11. In general, the farther the temperature from the design value the worse the VDVN broadband performance.

Considering the frequency and temperature ranges of the current application (200 to $430 \mathrm{~Hz}$, and 5 to $35^{\circ} \mathrm{C}$, resp.) and the frequency and temperature dependencies of a typical viscoelastic material (particularly detailed in Figure 2), it is 


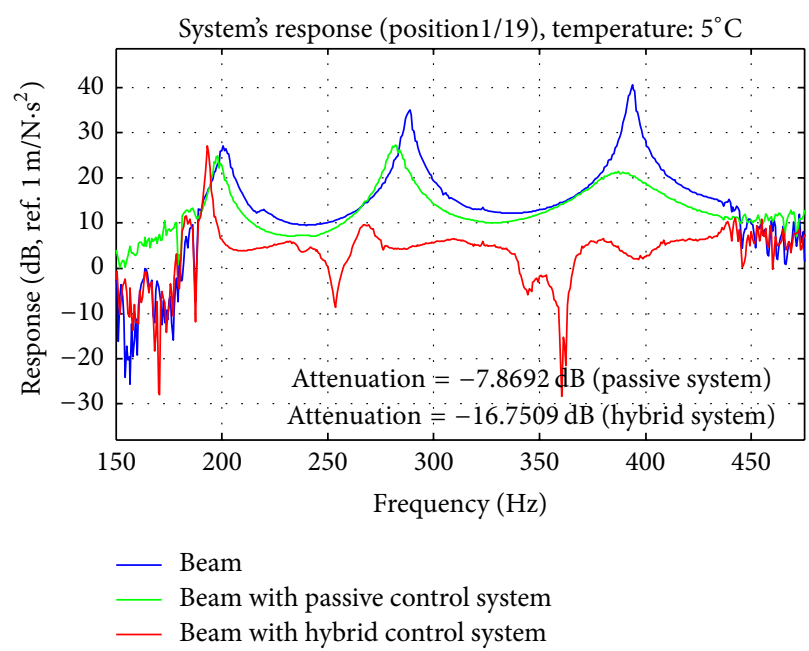

(a)

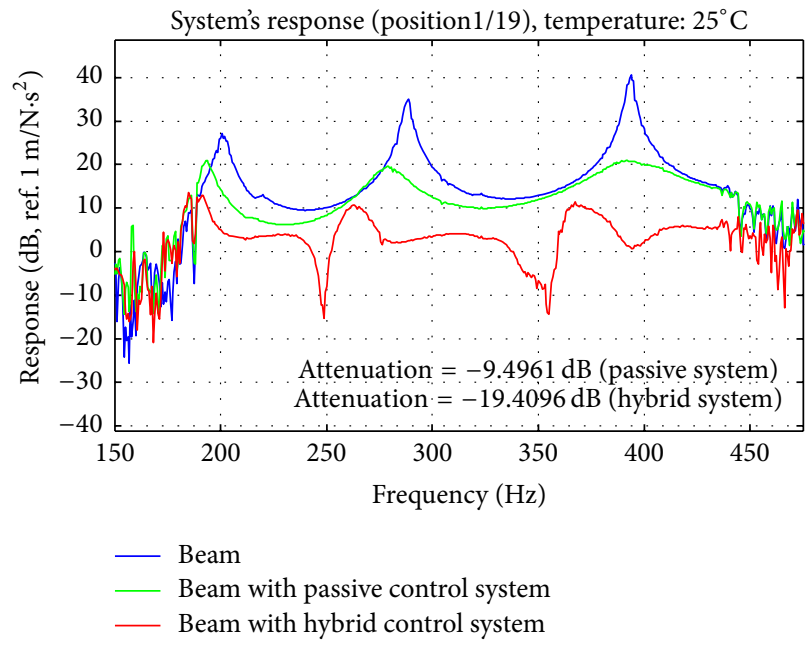

(c)

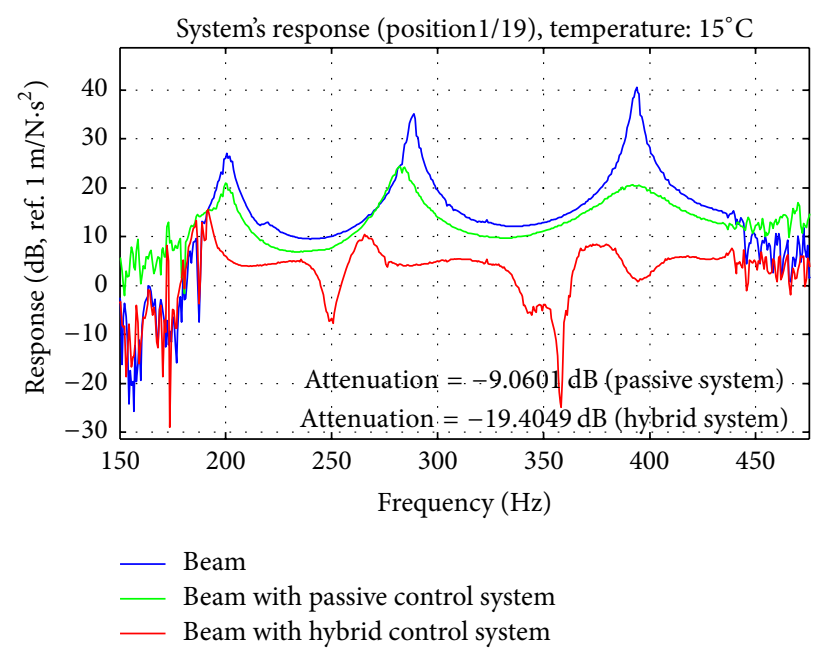

(b)

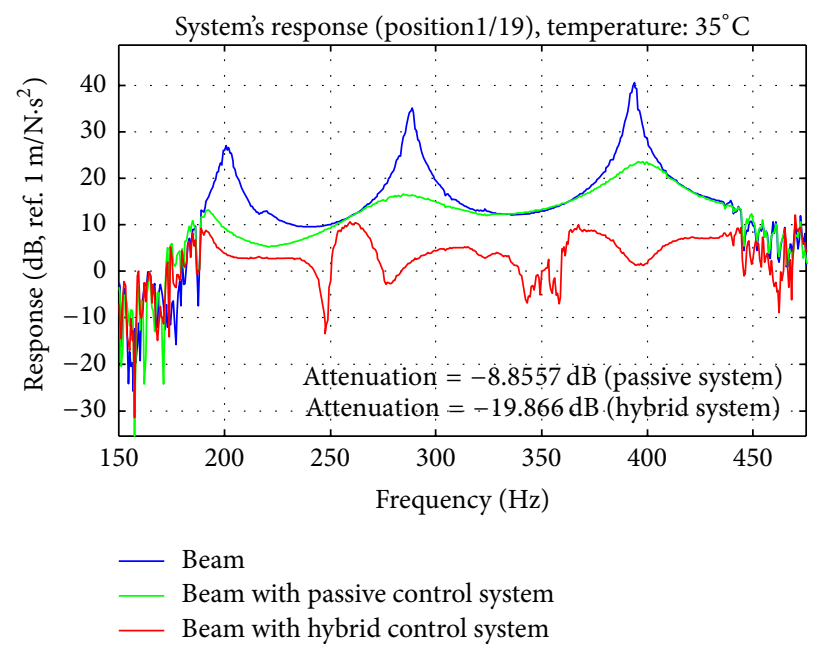

(d)

Figure 12: PVCS and HVCS performances at (a) $T=5^{\circ} \mathrm{C}$, (b) $T=15^{\circ} \mathrm{C}$, (c) $T=25^{\circ} \mathrm{C}$, and (d) $T=35^{\circ} \mathrm{C}$.

TABLE 3: VDVN performance (vibration attenuation), resonance peak analysis.

\begin{tabular}{lccc}
\hline Test temperature $\left[{ }^{\circ} \mathrm{C}\right]$ & $\begin{array}{c}\text { Resonance peak } \\
\text { attenuation }(4 \text { th mode) } \\
{[\mathrm{dB}]}\end{array}$ & $\begin{array}{c}\text { Resonance peak } \\
\text { attenuation }(5 \text { th mode) }\end{array}$ & $\begin{array}{c}\text { Resonance peak } \\
\text { attenuation }(6 \text { th mode) } \\
{[\mathrm{dB}]}\end{array}$ \\
\hline 5 & 2,0 & 8,0 & 19,0 \\
15 & 6,0 & 11,0 & 20,0 \\
25 & 6,0 & 16,0 & 19,5 \\
35 & 14,0 & 18,0 & 17,0 \\
\hline
\end{tabular}

expected to observe higher VDVN sensibility to temperature than to frequency variations. This is not only the more practical but also the more revealing situation.

Focusing on the resonance peaks only, it is observed that the greatest attenuations, regarding each mode of vibration, do not occur at $25^{\circ} \mathrm{C}$, as recorded in Table 3. However, it must be remembered that the viscoelastic DVN is not primarily designed for tonal action but for broadband action and that has to do with the amount of damping in the device. In fact, for tonal passive control, an "undamped" vibration neutralizer should be used instead.

4.2. Hybrid Vibration Control System (HVCS). The results obtained with the PVCS and the HVCS (comprising both passive and the active-adaptive vibration control systems) are shown in Figure 12, for various temperatures. It can 
TABLE 4: PVCS and HVCS performance (vibration attenuation related to the uncontrolled beam vibration levels), broadband analysis.

\begin{tabular}{lccc}
\hline Temperature & \multicolumn{3}{c}{ Control system } \\
& $\begin{array}{c}\text { Passive } \\
{[\mathrm{dB}]}\end{array}$ & Hybrid [dB] & $\begin{array}{c}\text { Difference (HVCS to } \\
\text { PVCS) [dB] }\end{array}$ \\
\hline $5^{\circ} \mathrm{C}$ & 7.9 & 16.8 & 8.9 \\
$15^{\circ} \mathrm{C}$ & 9.1 & 19.4 & 10.3 \\
$25^{\circ} \mathrm{C}$ & 9.5 & 19.4 & 9.9 \\
$35^{\circ} \mathrm{C}$ & 8.9 & 19.9 & 11.0 \\
\hline
\end{tabular}

be observed in the corresponding curves that the PVCS (VDVN) generally produces a small lateral displacement of the resonance peaks, apart from the characteristic "smoothing." These effects are typical in cases of damping addition. When the AVCS is turned on and the full HVCS is in place, drastic modifications are observed on the RFR curves, especially at the resonance peaks and at frequencies where antiresonances are introduced in those curves (there is a supplementary material, a video (in Supplementary Material available online at http://dx.doi.org/10.1155/2016/5375309), which shows, in real time, the AVCS actuating on the beam with PVCS, since the moment it is turned on until the final condition of the system, when the RFRs assume the shapes of Figure 12).

The marked control action at the resonance peaks after the AVCS is turned on can be explained as follows. The control signal generation is based on an online plant identification method and this makes the highest energy frequency components of the system response (the resonance frequencies) to be carried to the main filter coefficients. Thus, the control signal is generated with the same characteristics; that is, the control signal has the same highest energy frequency components as the plant response. Hence, when the control signal is reintroduced into the system (see Figure 3), its action is more efficacious exactly at the resonance peaks.

Table 4 presents the performance of the PVCS and the HVCS at each test temperature, considering the vibration attenuation at the frequency band of interest calculated according to (7), whereas Table 5 presents the attenuations at each resonance frequency, given the associated vibration mode. More expressive values are observed when considering the performance of the vibration control systems by the attenuation at the resonance peaks (see Figure 12 and Table 5). In some cases, the attenuation when the HVCS is in place is around a massive $34 \mathrm{~dB}$.

Tables 4 and 5 may induce comparisons between the PVCS and the AVCS (recalling that the HVCS comprises both the PVCS and the AVCS). However, this comparison is not adequate because the AVCS always works along with the PVCS. The PVCS is applied to the metallic beam alone, but the AVCS is applied to the metallic beam with the PVCS, a "new plant" for which the mass, damping, and stiffness characteristics are different from those of the metallic beam alone. So, the PVCS and AVCS work over different plants, in such a way that their performances should not be compared.

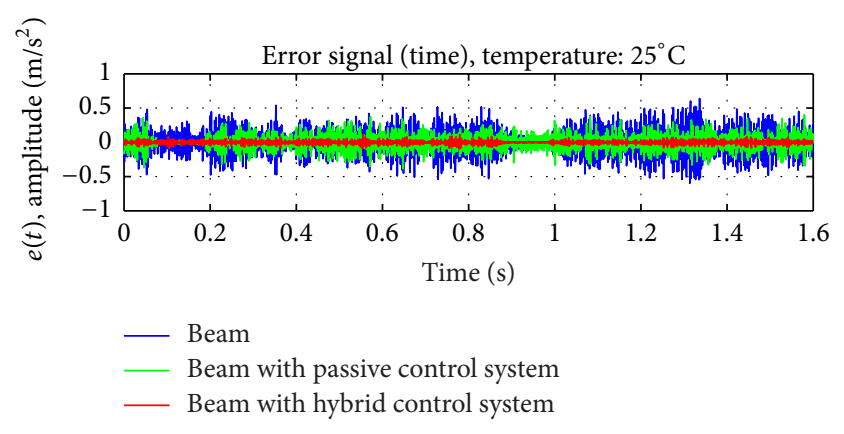

FIGURE 13: Error sensor time history.

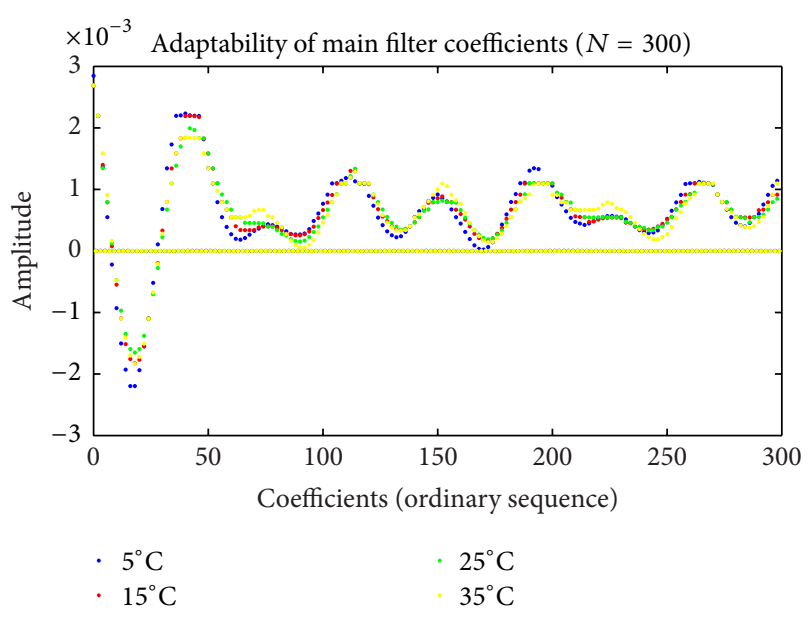

FIGURE 14: Adaptability of main filter coefficients.

Tables 4 and 5 help to illustrate (once more) the effectiveness of the VDVN (as a robust passive vibration control system) and also to demonstrate that the inclusion of the AVCS is a feasible solution for the detuning inherent to the VDVN when it undergoes temperature variations. As shown in those tables, when the AVCS works along with the PVCS (forming the HVCS), the VDVN detuning is no longer a problem, because the AVCS can compensate the VDVN loss of performance. In fact, the combination of the PVCS and the AVCS provides expressive results in terms of vibration attenuation over all the temperature and frequency ranges of operation.

The behaviors of the vibration control systems are also monitored through the error sensor signal, in the time domain, as displayed in Figure 13. Those curves reinforce the greater efficacy of the HVCS.

The adaptation capability introduced by the AVCS, as part of the HVSC, can be inferred from the above results. However, in order to make this point even more clear and help to visualize how the FXLMS algorithm handles the main filter coefficients to generate the best control signal at each test condition, the values of the main filter coefficients are traced at each test temperature. The results are presented in Figure 14, where the adaptability of the AVCS is clearly observed, in response to the changes in dynamic behavior undergone by the plant due to the temperature dependence of the VDVN. 
TABLE 5: PVCS and HVCS performance (vibration attenuation related to the uncontrolled beam vibrations levels), resonance peak analysis.

\begin{tabular}{lcccc}
\hline Temperature $\left[{ }^{\circ} \mathrm{C}\right]$ & Vibration control system & Vibration mode & 5th $[\mathrm{dB}]$ & 5 th $[\mathrm{dB}]$ \\
\hline \multirow{2}{*}{5} & Passive & 2,3 & 7,7 & 19,3 \\
& Hybrid & 0,0 & 25,6 & 34,1 \\
\hline \multirow{2}{*}{15} & Passive & 6,2 & 10,8 & 20,0 \\
& Hybrid & 11,5 & 24,6 & 32,2 \\
\hline \multirow{2}{*}{25} & Passive & 6,2 & 15,5 & 19,5 \\
& Hybrid & 13,3 & 24,3 & 29,1 \\
\hline \multirow{2}{*}{35} & Passive & 14,0 & 18,6 & 17,0 \\
& Hybrid & 17,8 & 24,7 & 30,6 \\
\hline
\end{tabular}

\section{Conclusions}

The vibration attenuation performance and robustness of the PVCS (VDVN), as well as its expected changes in dynamic behavior under frequency and temperature variations, are verified once more. That adds to the long and successful chain of broadband applications in which the same technique for VDVN design is employed [5, 6, 20].

The adaptive behavior of the AVCS becomes well characterized when there are changes in the compound system (metallic beam + VDVN) due to the variation in temperature, confirming and extending some previous efforts of tonal nature [28]. In most cases, the filter coefficients are adjusted in such a way that the VDVN loss of performance by detuning is compensated and an extended global vibration attenuation at around $19 \mathrm{~dB}$ is maintained. Even when that level is not reached, a very significant effort is clearly made by the AVCS.

It is worth mentioning that the adaptive capability is very important to compensate not only system modifications but also some modeling errors or inaccuracies in design, thereby improving the applicability of the AVCS. It is understood that improvements on the quality and effectiveness of the FXLMS algorithm will be achieved if the "static" secondary and feedback filters become adaptive as well.

It is also pointed out that the damping characteristics of the mechanical system under control, altered by the insertion of the VDVN, are an important factor for the order (number of coefficients) of the employed FIR filters and for the FXLMS effectiveness. In fact, when a VDVN is inserted in a mechanical system, this system becomes more damped, with impulsive response functions of smaller nonzero length. As the AVCS is applied to this more damped plant (beam with VDVN), the FIR filters can be of reduced order. That has a direct impact on the convergence of the employed LMS algorithm.

Finally, the HVCS, comprising both the above PVCS and AVCS, reveals itself as a powerful alternative in vibration control, in which the advantages of each particular system can be well associated in order to have an adaptable, flexible, and robust global control system, of reduced cost. This association also contributes to a more reliable control system, where the responsibility is shared between its component systems and some overall vibration control level can still be maintained in case of failure of any of those systems.

\section{Competing Interests}

The authors declare that they have no competing interests.

\section{Acknowledgments}

The first author wishes to express his gratitude to the Federal University of Santa Catarina, Brazil, and Federal University of Paraná, Brazil, for all the support over the development of this work. The second author acknowledges the financial support of CNPq. A special acknowledgement must be expressed for the relevant contributions of Dr. Orlando Jose Tobias ("in memoriam") to this work.

\section{References}

[1] C. E. Crede, Shock and Vibration Concepts in Engineering Design, Prentice-Hall, Upper Saddle River, NJ, USA, 1965.

[2] A. D. Nashif, D. I. G. Jones, and J. P. Henderson, Vibration Damping, John Wiley \& Sons, New York, NY, USA, 1985.

[3] B. G. Korenev and L. M. Reznikov, Dynamic Vibration Absorbers: Theory and Technical Applications, John Wiley \& Sons, 1993.

[4] D. J. Mead, Passive Vibration Control, John Wiley \& Sons, 2000.

[5] J. J. De Espíndola, C. A. Bavastri, and E. M. De Oliveira Lopes, "Design of optimum systems of viscoelastic vibration absorbers for a given material based on the fractional calculus model," Journal of Vibration and Control, vol. 14, no. 9-10, pp. 1607-1630, 2008.

[6] J. J. Espíndola, C. A. Bavastri, and E. M. O. Lopes, "On the passive control of vibrations with viscoelastic dynamic absorbers of ordinary and pendulum types," Journal of the Franklin Institute, vol. 347, pp. 102-115, 2010.

[7] M. A. Ahmad, A. N. K. Nasir, R. M. T. R. Ismail, and M. S. Ramli, "Comparison of hybrid control schemes for vibration suppression of flexible robot manipulator," in Proceedings of the International Conference on Computer Modeling and Simulation (ICCMS '09), pp. 356-360, Macau, China, February 2009.

[8] H. Pu, X. Luo, W. Jiang, K. Dong, and X. Chen, "Modelling and control of hybrid vibration isolation system for high-precision equipment," in Proceedings of the 8th IEEE International Conference on Control and Automation (ICCA '10), pp. 2152-2157, Xiamen, China, June 2010.

[9] J. L. Svensson, P. B. U. Andersson, and W. Kropp, "On the design of structural junctions for the purpose of hybrid passive-active 
vibration control," Journal of Sound and Vibration, vol. 329, no. 9, pp. 1274-1288, 2010.

[10] S.-M. Kim, S. Wang, and M. J. Brennan, "Dynamic analysis and optimal design of a passive and an active piezo-electrical dynamic vibration absorber," Journal of Sound and Vibration, vol. 330, no. 4, pp. 603-614, 2011.

[11] M. A. Trindade, "Experimental analysis of active-passive vibration control using viscoelastic materials and extension and shear piezoelectric actuators," Journal of Vibration and Control, vol. 17, no. 6, pp. 917-929, 2011.

[12] Y. L. Cheung, W. O. Wong, and L. Cheng, "Optimization of a hybrid vibration absorber for vibration control of structures under random force excitation," Journal of Sound and Vibration, vol. 332, no. 3, pp. 494-509, 2013.

[13] S. Mohammadi, S. Hatam, and A. Khodayari, "Modeling of a hybrid semi-active/passive vibration control technique," Journal of Vibration and Control, vol. 21, no. 1, pp. 21-28, 2015.

[14] M. A. Franchek, M. W. Ryan, and R. J. Bernhard, "Adaptive passive vibration control," Journal of Sound and Vibration, vol. 189, no. 5, pp. 565-585, 1996.

[15] J. C. O. Marra, Controle híbrido de vibrações em estruturas sob excitação de banda larga, utilizando neutralizador viscoelástico e filtro adaptativo [M.S. thesis], Federal Universityof Santa Catarina, Florianópolis, Brazil, 2007 (Portuguese).

[16] D. J. Inman, Vibration with Control, John Wiley \& Sons, New York, NY, USA, 2009.

[17] C. R. Fuller, S. J. Elliot, and P. A. Nelson, Active Control of Vibration, Academic Press, New York, NY, USA, 1997.

[18] R. L. Clark, W. R. Saunders, and G. P. Gibbs, Adaptive Structures-Dynamics and Control, John Wiley \& Sons, 1998.

[19] J. C. O. Marra, E. M. O. Lopes, J. J. Espíndola, O. J. Tobias, and W. A. Gontijo, "Hybrid vibration control applied to structures under broadband excitation using viscoelastic neutralizer and adaptive filter," in Proceedings of the 21st Brazilian Congress of Mechanical Engineering, Natal, Brazil, 2011.

[20] C. A. Bavastri, Redução de vibrações de banda larga em estruturas complexas por neutralizadores viscoelásticos [Ph.D. thesis], Federal Universityof Santa Catarina, Trindade, Brazil, 1997 (Portuguese).

[21] J. J. De Espiíndola, J. M. Da Silva Neto, and E. M. O. Lopes, "A generalised fractional derivative approach to viscoelastic material properties measurement," Applied Mathematics and Computation, vol. 164, no. 2, pp. 493-506, 2005.

[22] F. J. Doubrawa Filho, M. A. Luersen, and C. A. Bavastri, "Optimal design of viscoelastic vibration absorbers for rotating systems," Journal of Vibration and Control, vol. 17, no. 5, pp. 699710, 2011.

[23] B. Farhang-Boroujeny, Adaptive Filters-Theory and Applications, John Wiley \& Sons, New York, NY, USA, 1998.

[24] S. J. Elliott, Signal Processing for Active Control, Academic Press, Cambridge, Mass, USA, 2001.

[25] J. C. O. Marra, P. J. G. Paupitz, and L. C. S. Goes, "A multichannel active-adaptive vibration control system applied to an aeronautical structure," in Proceedings of the International Conference on Noise and Vibration Engineering, Leuven, Belgium, 2010.

[26] S. Griffin, A. Weston, and J. Anderson, "Adaptive noise cancellation system for low frequency transmission of sound in open fan aircraft," Shock and Vibration, vol. 20, no. 5, pp. 989-1000, 2013.

[27] J. Zeng, B. Moulin, R. De Callafon, and M. J. Brenner, "Adaptive feedforward control for gust load alleviation," Journal of Guidance, Control, and Dynamics, vol. 33, no. 3, pp. 862-872, 2010.
[28] J. Coan Jr., Controle misto de vibrações em viga metálica por neutralizadores viscoelásticos e filtros adaptativos: caso harmônico [M.S. thesis], Federal University of Santa Catarina, Florianópolis, Brazil, 2005 (Portuguese).

[29] S. M. Kuo and D. R. Morgan, "Active noise control: a tutorial review, Proceedings of the IEEE, vol. 87, no. 6, pp. 943-973, 1999.

[30] W. A. Gontijo, Implementação e avaliação de desempenho de algoritmos adaptativos aplicados em controle ativo de vibrações [M.S. thesis], Federal Universityof Santa Catarina, Florianópolis, Brazil, 2006 (Portuguese). 


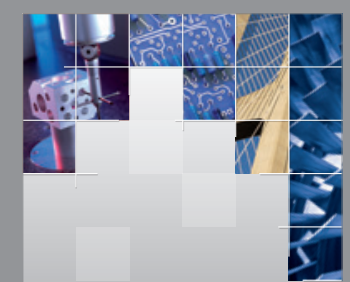

\section{Enfincering}
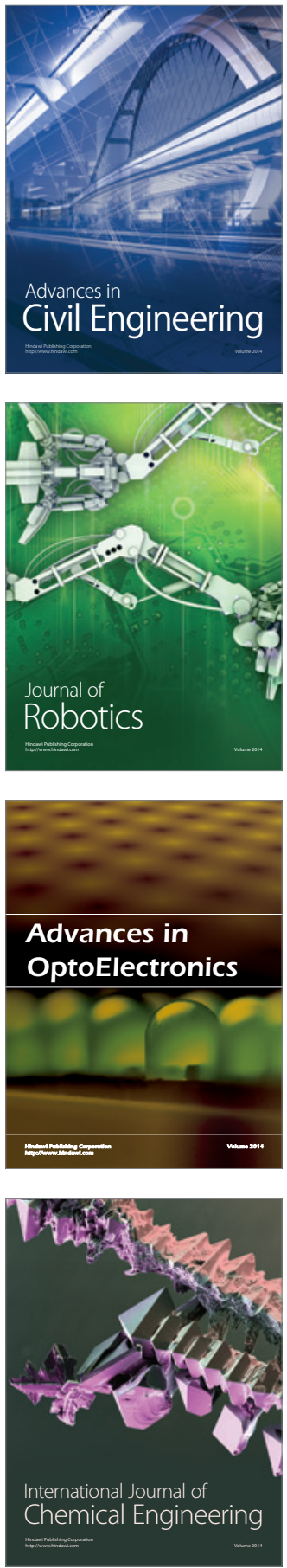

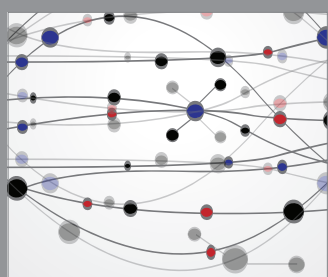

The Scientific World Journal

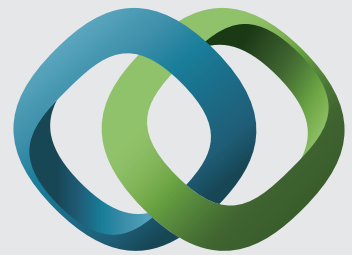

\section{Hindawi}

Submit your manuscripts at

http://www.hindawi.com
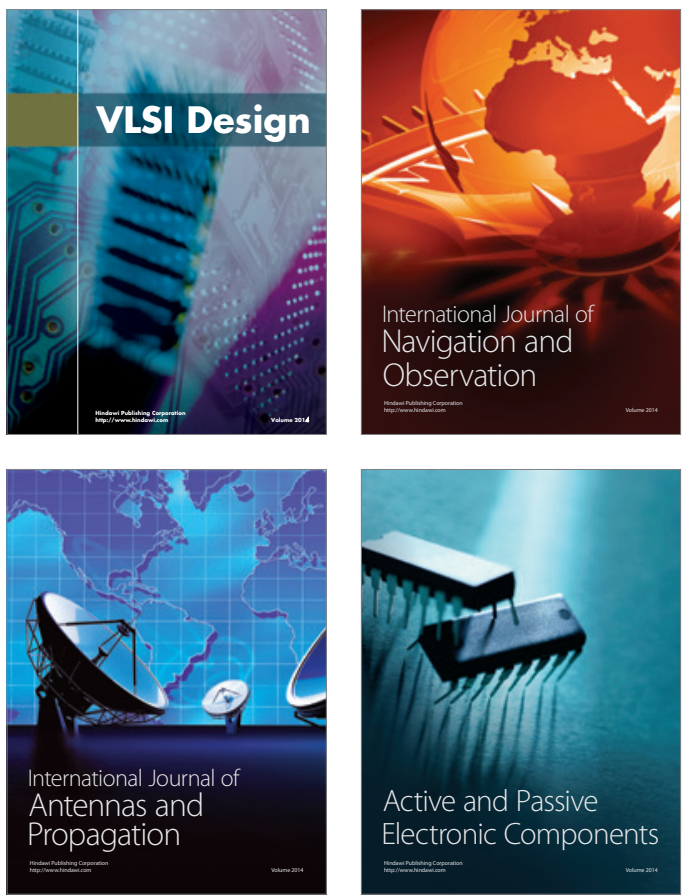
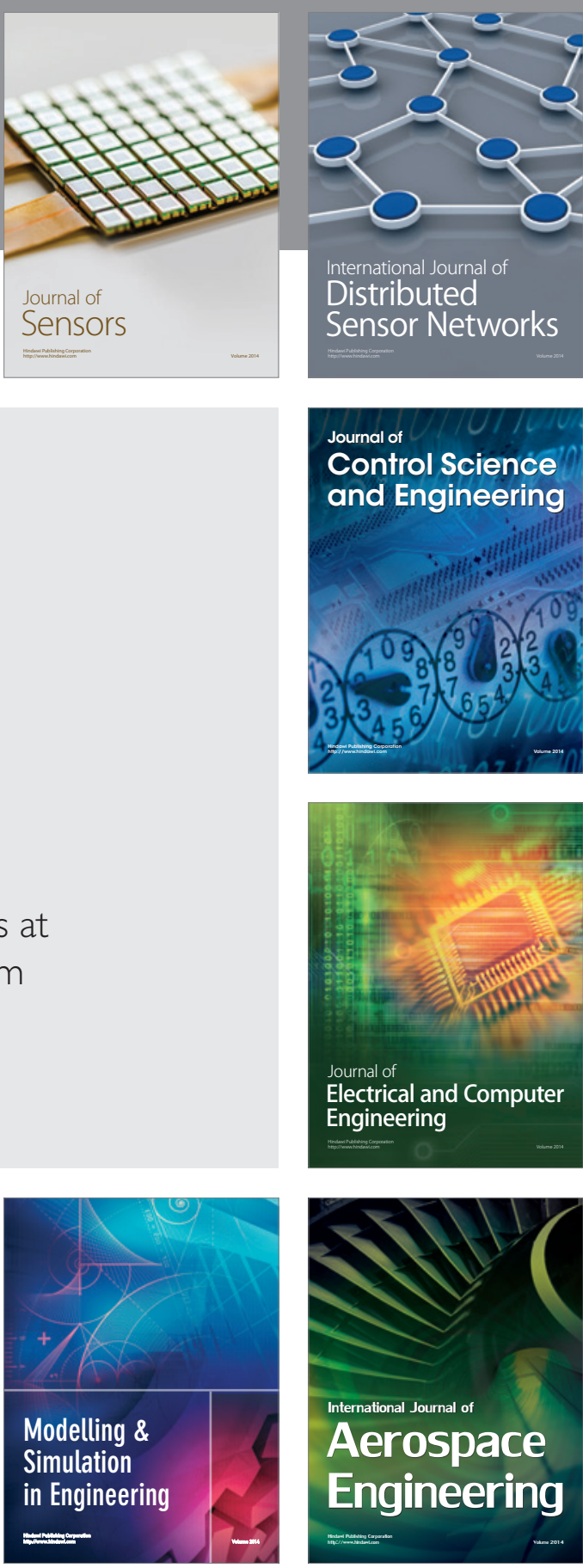

International Journal of

Distributed

Sensor Networks

Journal of

Control Science

and Engineering
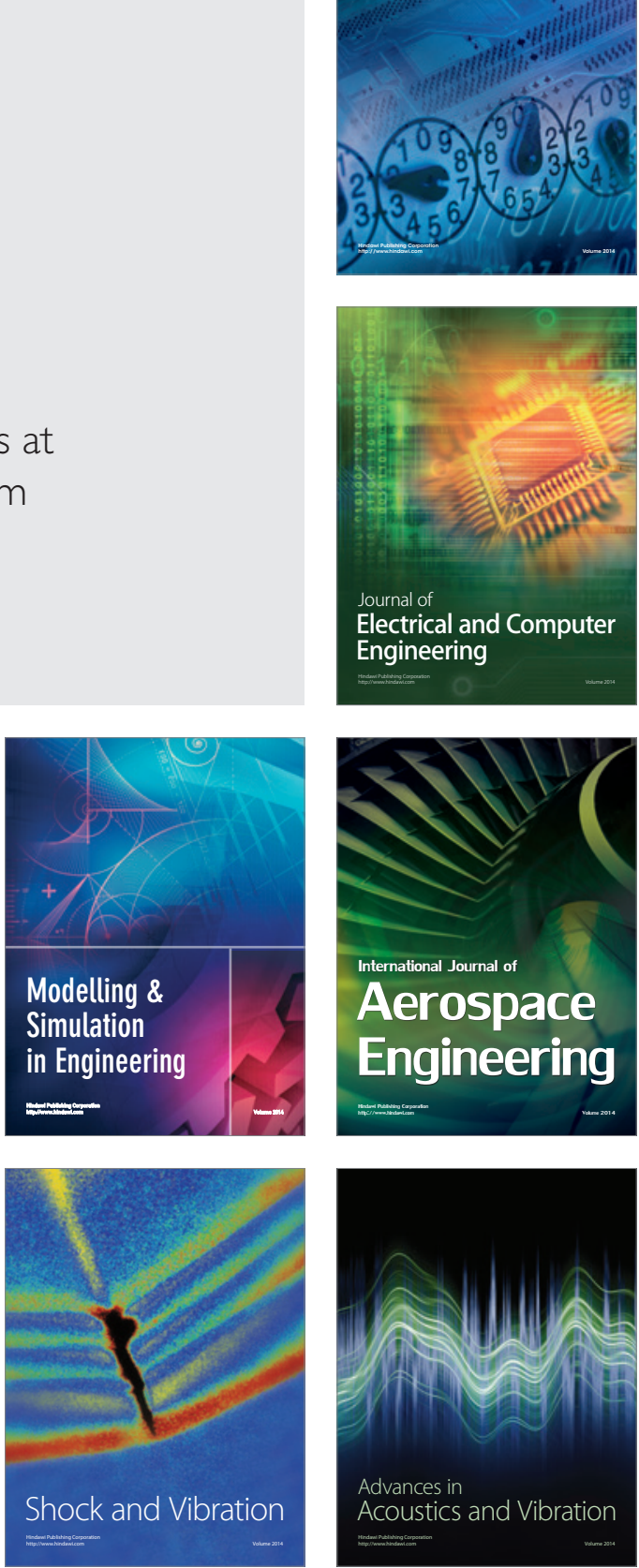